http://ejournal.upi.edu/index.php/jaz - e-mail: jurnal.zonasi@gmail.com dan jurnal_zonasi@upi.edu doi.org/10.17509/jaz.v3i3.26692

\title{
ARSITEKTUR TROPIS PADA TATA RUANG DAN PERMUKIMAN DI KAMPUNG PULO GARUT
}

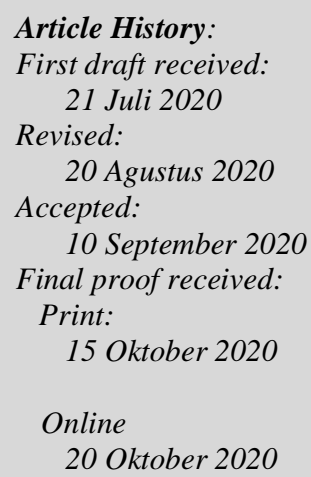

Jurnal Arsitektur ZONASI is indexed and listed in several databases:

SINTA 4 (Arjuna)

GARUDA (Garda Rujukan Digital)

Google Scholar

Dimensions

oneSearch

BASE

Member:
Crossref
RJI
APTARI
FJA (Forum Jurna Arsitektur)
IAI
AJPKM

Member:

Crossref

APTARI

\author{
Dita Rizkia Aprita ${ }^{1}$ \\ Anisa $^{2}$ \\ 1,2, Universitas Muhammadiyah Jakarta, Jakarta, Indonesia \\ Jl.Cempaka Putih Tengah 27 No 27/10,Rt 7, Cemp.Putih Timur.,Kec.Cemp.Putih,Kota \\ Jakarta Pusat,Daerah Khusus Ibukota Jakarta 10510,(021) 4244016 \\ Email: ditarizkiaaprita84@gmail.com \\ Anisa@ftumj.ac.id
}

\begin{abstract}
Abstrak: Tradisional menurut KBBI merupakan cara berpikir dan bertindak yang selalu berpegang teguh pada norma. Tradisional masih berkaitan dengan kesenian,ciri khas budaya dan permukiman. Permukiman tradisional merupakan hal terpenting ketiga setelah sandang dan pangan yang sangat dibutuhkan masyarakat. Permukiman merupakan suatu wadah tempat terbentuknya suatu komunitas dengan tujuan bermasyarakat satu dengan yang lainnya. Permukman tradisional merupakan hal yang sering diketahui oleh kebanyakan orang,terutama permukiman tradisional Sunda. Pada dasarnya permukiman Sunda sama dengan permukiman tradisional lainnya hanya saja konsep tata ruang dan konsep permukiman saja yang berbeda. Adapun permukiman yang ingin dikaji dalam penelitian ini adalah permukiman sunda lebih tepatnya Kampung Pulo Garut. Penelitian ini dilakukan dengan tujuan mengidentifikasi dan mendeskripsikan penerapan arsitektur tropis pada tata ruang dan pola permukiman tradisional Sunda. Adapun penerapan teori yang akan dikaji menggunakan beberapa aspek tropis dan pengkajian yang akan di analisis hanya beberapa aspek tropis,yaitu kenyamanan termal,suhu udara,kelembaban,pergerakan udara,intesitas matahari dan curah hujan.Adapun metode yang akan digunakan metode deskriptif kualitatif. Adapun tujuan yang akan menjadi hasil dari penelitian ini untuk mengetahui dan mendeskripsikan penerapan arsitektur tropis pada permukiman tradisional serta mengetahui hubungan faktor iklim dengan pola tata ruang.
\end{abstract}

Kata Kunci: Tradisional,Permukiman,Tropis.

Abstract: Traditional according to KBBI is a way of thinking and acting that always holds fast to the norm. Traditional is still related to art, cultural characteristics and settlements. Traditional settlements are the third most important thing after clothing and food that is needed by the community. Settlement is a place where a community is formed with the aim of community with one another. Traditional permukman is something that is often known by most people, especially traditional Sundanese settlements. Basically Sundanese settlements are the same as other traditional settlements, except that the spatial concept and settlement concept are different. The settlements that want to be studied in this study are Sundanese settlements more precisely Kampung Pulo Garut. This research was conducted with the aim of identifying and describing the application of tropical architecture to the traditional Sundanese spatial and settlement patterns. As for the application of the theory to be studied using several tropical aspects and the assessment to be analyzed is only a few tropical aspects, namely thermal comfort, air temperature, humidity, air movement, sun intensity and rainfall. As for the method to be used a descriptive qualitative method. The purpose that will be the result of this research is to find out and describe the application of tropical architecture in traditional settlements and to know the relationship between climate factors and spatial patterns.

Keyword: Traditional, Settlement, Tropical 


\section{Pendahuluan}

Iklim merupakan hal terpenting yang akan berpengaruh langsung terhadap kenyamanan suatu tempat tinggal. Faktor-faktor yang mempengaruhi iklim antara lain, panas yang dihasilkan oleh paparan sinar matahari,kelembaban udara yang disebabkan tinggi curah hujan dan pengaruh pergerakan udara. Pada dasarnya Indonesia memiliki iklim tropis oleh karena itu iklim sangat berpengaruh terhadap rancangan suatu pada daerah yang memiliki iklim tropis.

Masyarakat tradisional merupakan masyarakat yang masih sangat menghargai tradisi atau kebudayaan yang diturunkan leluhur dalam hal sosial dan budaya. Faktor yang menjadi kebudayaan masyarakat tradisonal dibagi menjadi dua yaitu kebudayaan bersifat fisik (tangible) dan non fisik (Intangible). Faktor (Intangible),yaitu berupa permukiman tradisional(Awalia et al., 2017)

Permukiman sunda terdapat di daerah Jawa Barat. Daerah Jawa Barat terkenal dengan keindahan alam dan keanekaragaman kebudayaan pada suku-suku tertentu. Keanekaragaman ini juga terdapat pada rumahrumah tradisional yang etnik dan memiliki berbagai macam filosofi yang terkandung. Kampung Pulo merupakan permukiman tradisional sunda yang terletak di Garut, Jawa Barat. Permukiman ini merupakan permukiman tradisional dimana bangunan permukiman yang digunakan masih berupa bahan-bahan alam yang didapatkan dari lingkungan kampung tersebut. permukiman ini memiliki batas-batas dan bentuk massa permukiman yang mempunyai makna sesuai dengan Rumah tradisional sunda.

Oleh karena itu latar belakang ini bertujuan untuk mengidentifikasi lebih lengkap bagaimana karakter permukiman tradisional yang menerapkan prinsip-prinsip arsitektur tropis. Berdasarkan uraian diatas dapat diketahui permasalahan yang akan diteliti yaitu bagaimana penerapan arsitektur tropis pada permukiman tradisional dan bagaimna pola tata ruang yang menerapkan konsep arsitektur tradisional.

\subsection{Permukiman Tradisional Sunda}

Permukiman ini merupakan permukiman tradisional dimana bangunan permukiman yang digunakan masih berupa bahan-bahan alam yang didapatkan dari lingkungan kampung tersebut. permukiman ini memiliki batas-batas dan bentuk massa permukiman yang mempunyai makna sesuai dengan Rumah tradisional sunda. Batasan penelitian ini akan membahas mengenai penerapan arsitektur tropis pada bangunan dan permukiman. pembahasan kedua akan membahas konsep arsitektural menurut arsitektur tradisional sunda.

Kata "Sunda" dipakai pertama kali oleh Raja Purnawarman,raja dari kerajaan Tarumanegara (Anwar \& Hafizh A Nugraha, 2013). Faktor yang mempengaruhi arsitektur rumah sunda,yaitu berbentuk panggung,menggunakan bahan dari alam,faktor adat yang akan mempengaruhi pola ruang. Perbedaan topografi di rumah tradisional sunda karena tanah di jawa barat berkontur,hal ini yang akan mempengaruhi fungsi dan kebutuhan.

\subsection{Pola Penataan Kampung}

Pola penataan rumah tradisional sunda berdasarkan kepada fungsi,keadaan kontur,dan fungsi permukiman. pola permukiman kampung tradisional dibagi menjadi 3,yaitu pola linier merupakan kelompok permukiman yang membentuk garis lurus,kedua pola terpusat merupakan pola permukiman yang mengelilingi dan mempunyai daerah terpusat. Ketiga pola radial perpaduan permukiman kelompok radial dan terpusat.

\subsection{Bentuk Atap Rumah Tradisional Sunda}

Bentuk atap pada rumah tradisional sunda dibagi menjadi 6,yaitu : pertama jalopong merpukan atap memanjang kedua sisi. Kedua atap tagog anjing/jogog anjing merupakan atap yang memiliki sudut atap yang berbeda-beda. Ketiga atap badag heuay merupakan atap yang tidak memiliki bumbungan. Keempat atap perahu kumureb merupakan atap yang berbentuk seperti atap limasan.kelima atap capit gunting merupakan atap yang memiliki ujung atap yang saling menyilang. Keenam atap julang ngapak merupakan atap yang sisi kanan dan kiri melebar dan mempunyai atap tambahan pada bagian atas(Anwar \& Hafizh A Nugraha, 2013).

\subsection{Tata Ruang Rumah Tradisional Sunda}

Tata Ruang rumah tradisional dibedakan menjadi tiga zonasi,yaitu bagian depan,bagian tengah,dan bagian belakang. Raung-ruang yang menjadi ciri khas dari rumah tradisional hanya terdapat golodog,teras,ruang keluarga,kamar tidur,dan dapur,untuk kamar mandi biasanya di letakkan diluar bangunan(Kustianingrum et al., 2013). 


\subsection{Stuktur Rumah Tradisional Sunda}

Pada dasarnya struktur bangunan terdiri dari 3 bagian sarana struktur yaitu struktur landasan bangunan dan struktur badan bangunan serta struktur atap bangunan. Dari sisi teknik membangun, proses pembangunan menunjukkan bahwa landasan adalah bagian bangunan yang didirikan lebih dahulu, kemudian kerangka lantai dipasang dan kemudian diatasnya didirikan tiang-tiang penyangga struktur atap. Sehingga yang terjadi lebih dahulu adalah kerangka utama bangunan, barulah dipasangkan penutup atap dan penutup badan bangunan(Sulistijowati, 2016).

Struktur rumah tradisional sunda dengan menggunakan rumah panggung. Struktur rumah tradisional sunda sama seperti struktur rumah biasa,terdapat pondasi,lantai ,material (atap,dinding dan laintai),rangka (atap,dinding dan laintai).

\subsection{Prinsip-Prinsip Arsitektur Tropis}

Kata tropis berasal dari kata yunani yaitu "tropikos" yang berarti garis balik. Pengertian tersebut berlaku untuk daerah antara kedua garis balik, yang meliputi sekitar 40\% dari luas seluruh permukaan bumi. Garis-garis balik tersebut adalah garis lintang $23^{\circ} 27^{\prime}$ utara dan selatan yang terletak diantara garis isotherm $20^{\circ} \mathrm{C}$. Dari definisi tersebut arsitektur tropis dapat diartikan sebagai suatu bentuk, teknik, dan fungsi yang membentuk suatu tautan pada daerah garis isotherm $20^{\circ} \mathrm{C}$ (Anitya Destiyanti et al., 2014).

\section{Kenyamanan Termal}

Kenyamanan termal dinyatakan bahwa rasa panas atau dingin yang dirasakan oleh tubuh manusia sesungguhnya merupakan wujud respon dari sensor perasa yang terdapat pada kulit terhadap stimuli suhu yang ada di sekitarnya. Sensor perasa berperan menyampaikan informasi rangsangan rasa kepada otak di manan otak akan memberikan perintah kepada bagian-bagian tubuh tertentu agar melakukan antisipasi guna mempertahankan suhu tubuh agar tetap berada pada sekitar $37^{\circ} \mathrm{c}$, di mana hal ini diperlukan agar organ dalam tubuh dapat menjalankan fungsinya secara baik (Tri Harso Karyono, 2010)(Ghassani et al., 2020).

\section{Suhu udara}

Suhu nyaman orang Indonesia menurut Yayasan LPMB PU, maka suhu yang kita butuhkan agar dapat beraktifitas dengan baik adalah suhu nyaman optimal $\left(22,8^{\circ} \mathrm{C}-25,8^{\circ} \mathrm{C}\right.$ dengan kelembaban $\left.70 \%\right)$. Angka ini berada di bawah kondisi suhu udara di Indonesia yang dapat mencapai angka $35^{\circ} \mathrm{C}$ dengan kelembaban 80\%(Masarrang \& Rengkung, 2013).

\section{Kelembaban}

Kelembaban yang ccok berkisar antara 40\%-70\%. Pada kelembaban yang tinggi dinding akan cenderung basah serta mengurangi isolasi kalor. Kelembaban yang tidak dihalu pergi oleh angin dapat menjadi penyebab ketidaknyamanan dalam ruangan. Kelembaban yang tinggi juga dapat merusak bahasn bangunan(Sardjono, 2011).

\section{Radiasi Matahari}

Jumlah Radiasi sinar matahari yang diterima fasad banguna, dengan demikian akan berkurang jumlah panas yang diterima yang akan menyebabkan temperaturnya menjadi lebih rendah(Zulfiqri,2008).

\section{Pergerakan Udara}

Pergerakan udara sangat berpengaruh pada kenyamanan termal karena pergerakan inlet dan outlet seharusnya seimbang jadi yang dihasilkan dari suatu runag akan memiliki kualitas udara yang sangan baik(Anisa Budiani Arifah, 2017).

\section{Curah Hujan}

Curah hujan rata-rata tahunan di sekitar Garut berkisar antara $2.589 \mathrm{~mm}$ dengan bulan basah 9 bulan dan bulan kering 3 bulan, sedangkan di sekeliling daerah pegunungan mencapai 3500-4000 $\mathrm{mm}$. Variasi temperatur bulanan berkisar antara $24^{\circ} \mathrm{C}-27^{\circ} \mathrm{C}$. Besaran angka penguap keringatan (evapotranspirasi) menurut Iwaco-Waseco (1991) adalah $1572 \mathrm{~mm} /$ tahun (Dedi Mulyono, 2014).

Curah Hujan yang tinggi dapat mengakibatkan kelembaban pada suatu bangunan oleh karena itu curah hujan dapat berpengaruh pada bentukan atap,sudut kemiringan atap,besarnya ukuran tritisan,hal ini dilakukan agar tidak ada air hujan yang mengendap ataupun masuk kedalam bangunan.

\subsection{Data Permukiman Kampung Pulo}

Permukiman kampung pulo terdapat di Desa Cangkuang, Kecamatan Leles letaknya terdapat di Jl. Drajat Leuwigoong, Cangkuang, Kecamatan Leles-Garut. Luas permukiman kampung pulo berkisar 340,755 Hektar. Berdasarkan hasil survey kondisi eksisting kampung pulo terdapat di kelilingi danau Cangkuang. Fasilitas-fasilitas yang terdapat di kampung pulo,yaitu: terdapat candi cangkuang, pemakaman dalem Arief Muhammad, Kampung Pulo dan museum situ cangkuang. 
Berdasarkan pola permukiman kampung pulo terdapat 7 Bangunan salah satu diantaranya fasilitas mushola untuk masyarakat kampung pulo. Denah rumah berbentuk empat persegi panjang, membujur dari arah barat timur dengan arah hadap utara atau selatan. Dengan arah hadap demikian, setiap rumah saling berhadapan dengan pembatas tanah lapang

Tata Ruang Terdapat Golodog,Ruang tamu,ruang tidur tamu,ruang tidur utama,ruang tengah,dapur dan goah. Pada permukiman kampung pulo sudah mengalami perbaikan dari segi material atap akan tetapi ada satu bangunan yang masih di pertahankan keasliannya.

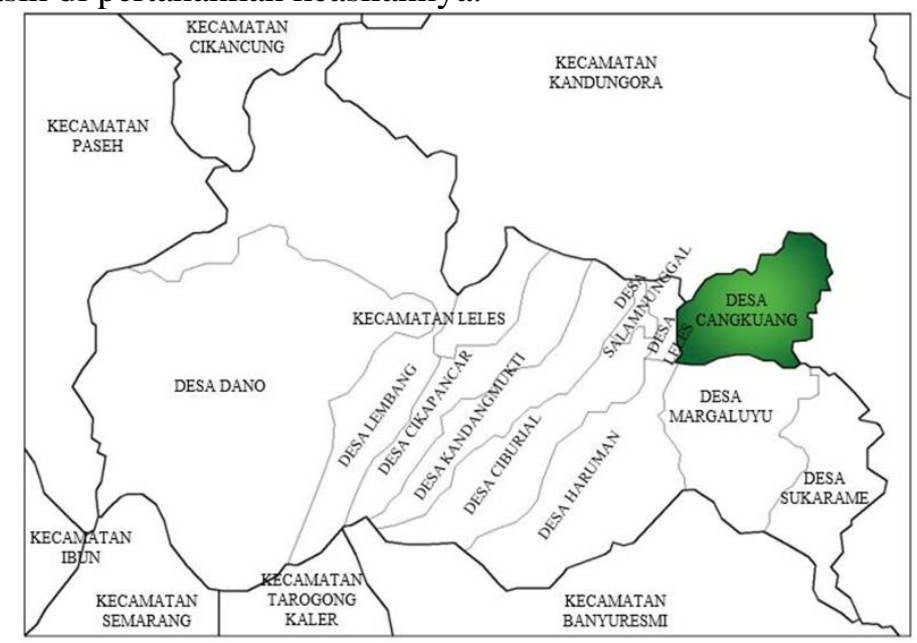

Gambar 1. Peta Administratif Kecamatan Leles

Sumber: analisis, 2020

\section{Metode Penelitian}

Metode yang digunakan dalam penelitian ini adalah deskriptif kualitatif, metode ini dilakukan dengan cara mengumpulkan data secara langsung melalui survey ke lokasi. Adapun data yang akan di peroleh berupa observasi, wawancara, studi Pustaka dan dokumentasi. Kemudian data dianalisis secara kualitatif Metode ini dilakukan untuk mengetahui bagaimana permukiman tradisional dapat menerapkan Arsitektur Tropis.

Pada metode penelitian deskriptif kualitatif ini dengan menerapkan metode pendekatan deduktif dimana penerapan deduktif ini dilakukan setelah memahami teori yang didapatkan dari literatur kemudian dapat diaplikasikan pada studi kasus yang dipilih. Metode ini digunakan untuk mendapatkan data yang spesifik setelah itu akan menghasilkan kesimpulan yang dapa menjawab permasalahan penelitian ini.

\section{Hasil dan Pembahasan}

\subsection{Isi Pembahasan}

Pola penyebaran kampung pulo memiliki pola terpusat dimana enam buah rumah yang memanjang yang saling berhadapan dan pada bagian tengah terdapat masjid. Pola terpusat pada permukiman kampung pulo mengelilingi area terbuka pada bagian depan permukiman.

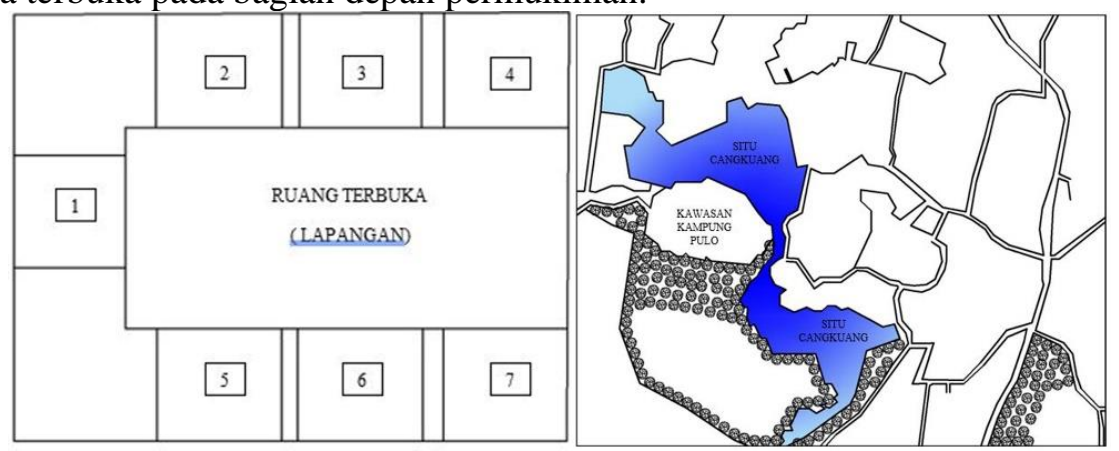

Gambar 2. Pola Penyebaran Kampung Pulo

Sumber: analisis, 2020 
Pola permukiman kampung pulo mengelilingi area perairan,yaitu berupa danau. Berdasarkan filosofi permukiman sunda penataan permukiman seperti ini disebut dengan lemah-cai dimana terdapat suatu wilayah yang dijadikan sebagai pemukiman dan Cai berupa wilayah perairan yang bertujuan sebagai keberlangsungan hidup masyarakat setempat.

Bentuk atap kampung pulo memiliki bentuk atap Jolopong,atap ini berbentuk memanjang di kedua sisi. Atap Jolopong sama dengan atap pelana. Pada atap kampung pulo memiliki atap yang sama,tetapi perbedaan yang terlihat hanya dari material atap. Karena perkembangan zaman atap kampung pulo terdapat perubahan material tiga rumah masih mengunakan material ijuk,tiga rumah lagi menggunakan atap genteng.

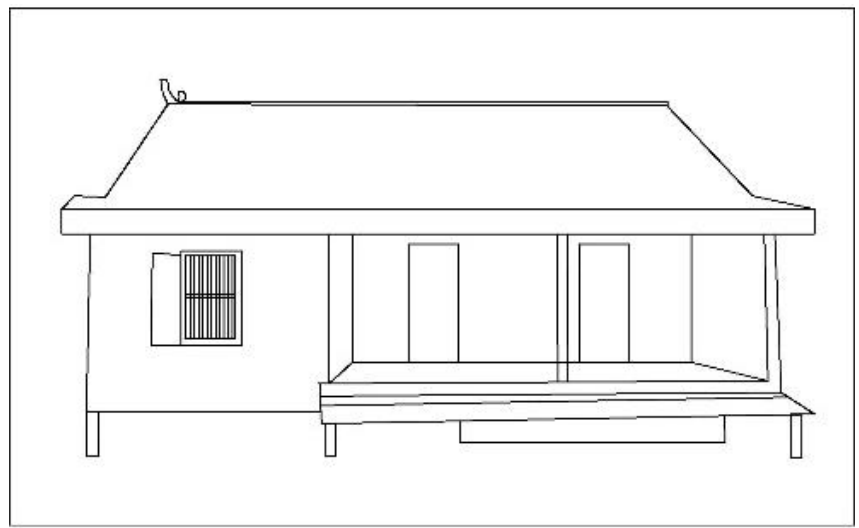

Gambar 3. Bentukan Atap Rumah Tradisional di Kampung Pulo Sumber: analisis, 2020

Tata ruang rumah pada permukiman kampung pulo pada dasarnya sama dengan tata ruang permukiman tradisional lainnya. Tata ruang rumah kampung pulo terdapat tiga bagian terdapat ruang depan,ruang tengah dan ruang belakang. Dalam arsitektur tata ruang disebut zonasi ruang seperti ruang publik,ruang ruang privat dan ruang service.

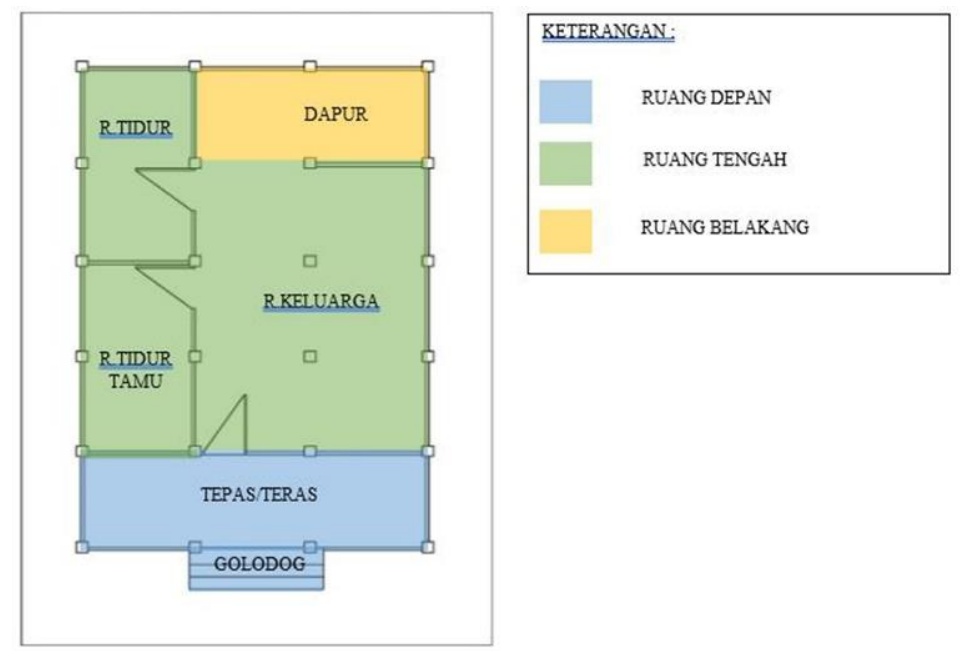

Gambar 4. Denah Rumah Tradisional di Kampung Pulo Sumber: analisis, 2020

Struktur rumah tradisional kampung pulo sama hal dengan rumah tradisional sunda pada umumnya terdapat pondasi kecil yang terdapat diatas tanah,menggunakan kolom bermaterial kayu, menggunakan struktur atap kuda-kuda,dan menggunakan atap pelana yang menggunakan material ijuk. Pda bagian badan bangunan menggunakan kayu untuk rangka bangunan dan menggunakan bilik bamboo untuk dinding bangunan. 


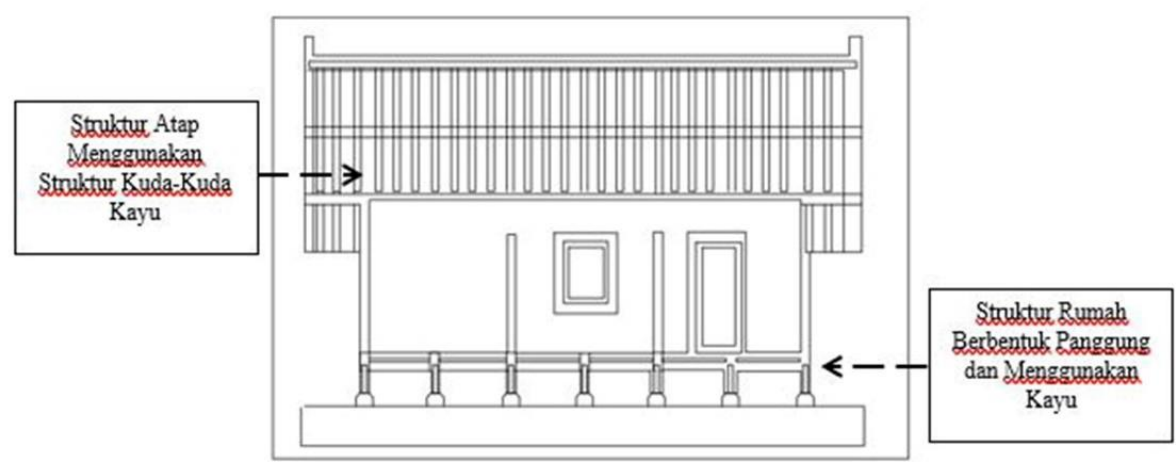

Gambar 5. Struktur Rumah Tradisional di Kampung Pulo Pulo Sumber: analisis, 2020

\subsection{Prinsip-Prinsip Arsitektur Tropis}

Aspek Radiasi Matahari

1.Permukiman kampung pulo

Aspek radiasi sangat berpengaruh terhadap suhu yang akan dihasilkan pada permukiman maupun rumah tinggal, untuk itu kampung pulo tetap menjaga kelestarian dengan memperbanyak vegetasi pada bagian depan dan menggunakan bahan-bahan alami untuk meminimalisir panas yang akan dihasilkan. Jika dilihat dari permukiman kampung pulo pada bagian halaman yang menjadi pusat orientasi rumah menggunakan paving block Ketika panas matahari memantulkan panas ke dasar maka panas akan di serap oleh paving block tersebut. Pada rumah di kampung pulo juga menggunakan bahan-bahan seperti kayu,bilik bamboo dan ijuk,dapat kita ketahui bahan-bahan terebut dapat menyerap panas lebih cepat.

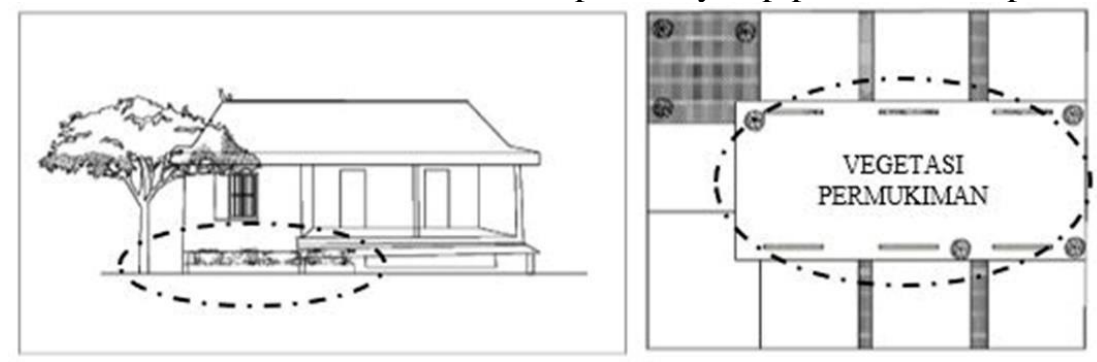

Gambar 6. Vegetasi di Permukiman Kampung Pulo

Sumber: analisis, 2020

Material Selubung bangunan

Material yang digunakan pada bagian lantai menggunakan lantai kayu,pada bagian dinding menggunakan bilik bambu dengan kerangka kayu,pada bagian atap menggunakan atap ijuk dan genteng. Material tersebut dapat kita ketahui bahwa material alam dapat menyerap panas dan mengurangi panas yang terjadi akibat adanya radiasi dari matahari.

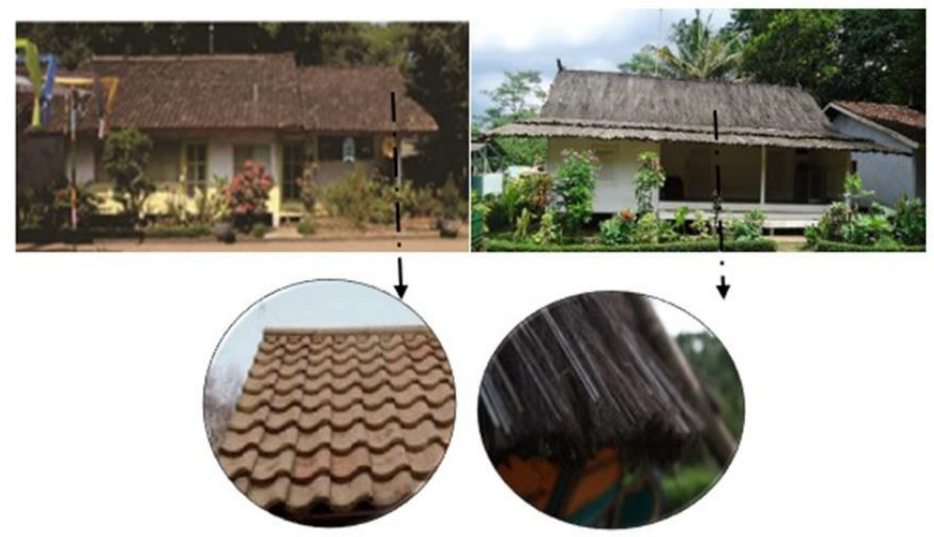

Gambar 7. Material Rumah Kampung Pulo Sumber: analisis, 2020 
Aspek Curah hujan

Aspek curah hujan dapat di pertimbangkan dalam sebuah desain. Terutama pada kampung pulo merupakan permukiman didaerah dataran tinggi dan intesitas curah hujan yang terjadi cukup tinggi. Aspek curah hujan ini yang berpengaruh pada desain atap yang mengunakan atap Jolopong dimana atap tersebut memiliki kemiringan yang cukup untuk air hujan langsung jatuh. Tritisan rumah kampung pulo juga berkisar 1-1,5 meter pada bagian depan hal ini bertujuan agar air hujan tidak masuk ke teras. Bangunan yang berbentuk panggung juga berfungsi meminimalisir tingkat kelembaban pada bangunan akibat curah hujan yang tinggi.

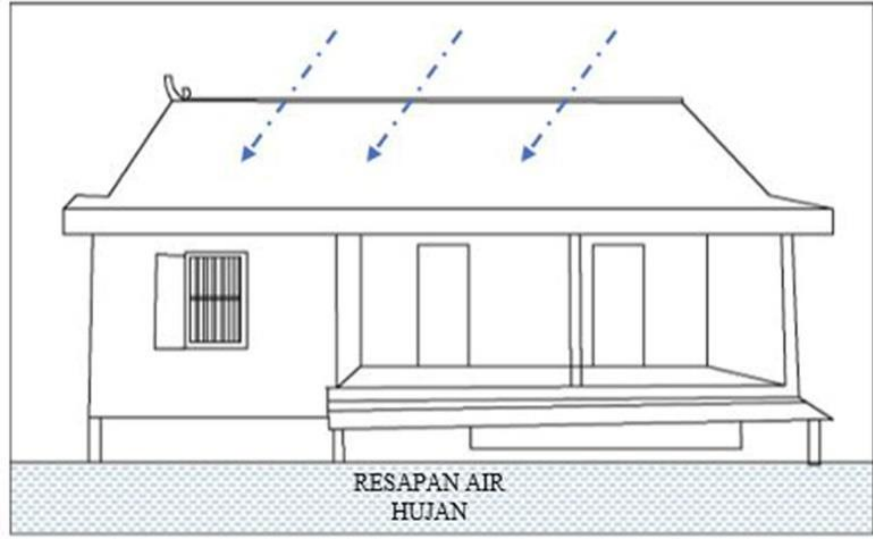

Gambar 8. Analisis Aspek Curah Hujan

Sumber: analisis, 2020

Kebanyakan dari masyarakat berasumsi adanya vegetasi di luar ruang hanya utnuk keindahan saja,akan tetapi banyak sekali manfaat yang dihsilkan dari vegetasi selain untuk menyerap karbondioksida di udara ternyata vegetasi juga dapat menyerap panas dan membuat bayangan sehingga panas yang dihasilkan dai paparan matahari yang dapat berpengaruh pada kenyamanan termal pada pengguna.

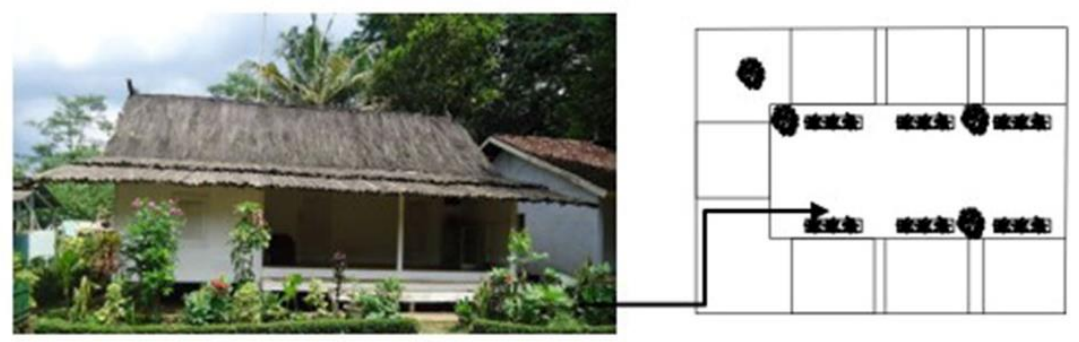

Gambar 9. Aspek Vegetasi

Sumber: analisis, 2020

Pergerakan udara

Pergerakan udara pada kampung pulo berpengaruh terhadap baesar dan jenis dan ketinggian bukaan yang digunakan. Pada rumah kampung pulo ini bukaan menggunakan jendela kisi-kisi. Lebar bukaan cukup besar hal ini dapat mempermudah pergarakan udara masuk dan udara keluar. Udara masuk dapat dari bagian bawah lantai yang menggunakan kayu dan udara masuk juga dapat dari jendela maupun pintu. Udara keluar bisa melalui celah-celah atap. Pada prinsip pergerakan udara,udara masuk dari daerah rendah dan keluar pada daerah yang tinggi.

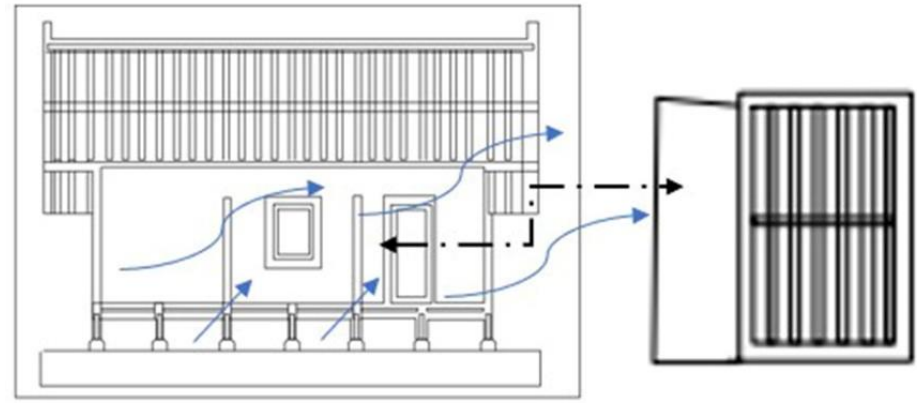

Gambar 10. Analisis Aspek Pergerakan Udara Sumber: analisis, 2020 
Orientasi bukaan

Orintasi bukaan pada permukiman dengan menggunakan pola terpusat orientasi bukaan terdapat pada bagian depan. Bagian bagian utara dan bagian timur tidak terdapat bukaan,dapat diketahui pada bagian barat dan timur merupakan sumber panas matahari hal ini yang memngkinkan tidak adanya bukaan. Jumlah bukaan satu unit rumah terdapat satu jendela dan pintu.

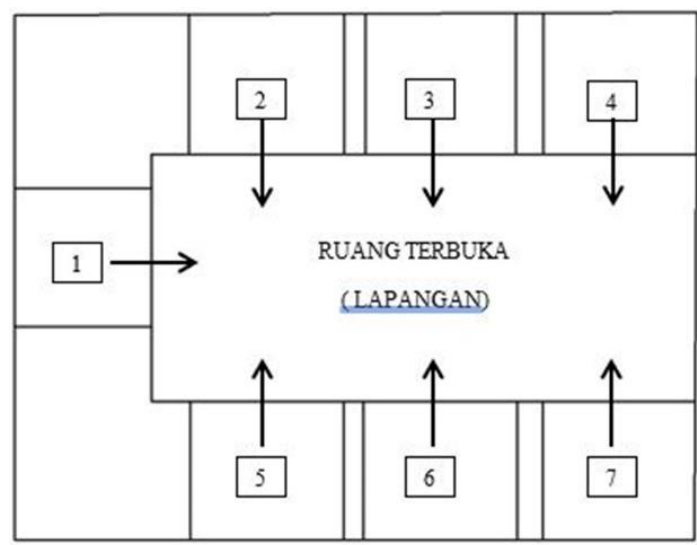

Gambar 11. Analisis Aspek Orientasi Bukaan Sumber: analisis, 2020

\section{Kesimpulan}

Berdasarkan hasil penelitian diatas dapat disimpulkan dari beberapa penerapan arsitektur tropis pada permukiman kampung garut sudah menanggapi iklim tropis lembab untuk mencapai kinerja kenyamanan termal, yaitu dengan menggunakan bahan alami serta menyesuaikan dengan suhu termal pada bangunan dan permukiman diantaranya:

1. dapat dikatakan bangunan telah memiliki bukaan yang sangat baik dimana di terapkan jalur pergerakan udara masuk dan udara keluar, hal ini dapat memberikan rasa nyaman kepada pengguna.

2. Penggunaan material yang digunakan dapat dikatakan merespon panas cukup baik, mengingat material bangunan dari kayu yang dapat menyerap panas lebih cepat dibandingkan menggunakan bata.

3. Penyesuaian yang baik sesuai termal pada permukiman dengan memberikan bukaan yang terletak pada lahan terbuka seperti lapangan hal ini yang akan memermudah pergerakan udara masuk. Merespon radisai matarahari dengan cara menanamkan vegetasi atau tumbuhan pada permukiman hal ini juga akan memberikan manfaat berupa penghalang masuk paparan matahari secara langsung.

Berdasarkan tujuan peneliti pada poin dua, yaitu mengetahui hubungan faktor iklim dengan pola tata ruang dan sirkulasi permukiman kampung pulo. Hubungan iklim dengan tata ruang sangat berpengaruh terhadap perletakkan pada bukaan dimana ruang-ruang tertentu yang memerlukan cahaya matahari lebih optimal dan mendapatkan pergerakan udara yang sangat optimal. Selain itu pola ruang dengan sedikit pembatas dan sirkulasi permukiman yang memiliki jarak yang cukup jauh dari rumah satu dengan yang lainnya hal ini mampu menangkap angin yang cukup untuk kenyaman termal pada massa bangunan dan permukiman di kampung pulo.

\section{Ucapan Terima Kasih}

Dalam menyelesaikan penulisan penelitian ini penulis banyak mendapat bantuan,dukungan dan doa dari berbagai pihak Sebagai bentuk rasa syukur kepada allah atas kenikmatan dan karunianya penulis dapat menyelesaikan penelitian ini serta penulis ingin menyampaikan terimakasih dan penghargaan kepada Dosendosen Fakultas Teknik UMJ khususnya pembimbing penulis Bu Anisa,S.T,.M.T,.berterima kasih kepada kedua orangtua beserta keluarga yang telah banyak mendukung penulis sampai tahap ini dan tidak lupa pula kepada teman-teman yang memberikan dukungan kepada penulis. 


\section{Referensi}

Anisa Budiani Arifah, M. S. A. dan A. M. N. (2017). Pengaruh Bukaan Terhadap Kenyamanan Termal Pada Ruang Hunian Rumah Susun Aparna Surabaya. Jurnal Mahasiswa Arsitektur, 1-10.

Anitya Destiyanti, Agung Budi S, \& Eddy Indarto. (2014). DESAIN ARSITEKTUR TROPIS. Rumah Susun Di Muarareja Kota Tegal Dengan Penekanan Desain Arsitektur Tropis, 3(4), 1091-1100.

Anwar, H., \& Hafizh A Nugraha. (2013). Rumah Etnik Sunda (Ita puspita (ed.); 1st ed.). Griya kreasi (penebar Swadaya Grup).

Awalia, R. N., Nurhayati HS arifin, \& Kaswanto. (2017). Kajian Karakter Pembentuk Lanskap Budaya Masyarakat Adat Kajang Di Sulawesi Selatan. Jurnal Lanskap Indonesia, 9(2), 91-100. https://doi.org/10.29244/jli.2017.9.2.91-100

Dedi Mulyono. (2014). Analisis karakteristik curah hujan di wilayah Kabupaten Garut Selatan. Jurnal Konstruksi, 13(1), 1-9.

Ghassani, A. I., Permana, A. Y., \& Susanti, I. (2020). Konsep Ekowisata Dalam Perancangan Resort di Kabupaten Ciamis. Jurnal Arsitektur TERRACOTTA, 1(1), 1-11. https://doi.org/10.26760/terracotta.v1i1.3359

Kustianingrum, D., Sonjaya, O., \& Ginanjar, Y. (2013). terdapat di Desa Cijambe Kecamatan Cikelet Kabupaten Garut Jawa Barat yang merupakan dan tidak terpengaruh oleh perkembangan zaman , dilihat dari segi arsitekturnya kampung ini perkampungan selalu menjadi wadah yang juga memiliki isi ( eusi ) yang artinya. 1(3), 1-13.

Masarrang, F., \& Rengkung, J. (2013). Pendekatan Kenyamanan Thermal Pada Arsitektur Tradisional. 10(2), 27-37.

Sardjono, A. B. (2011). Respon Rumah Tradisional Kudus. MODUL Vol.11 No.1 Januari 2011, 11(1), 7-16.

Sulistijowati, M. (2016). Struktur di Arsitektur Nusantara. Struktur Di Arsitektur Nusantara Murtijas, 19-24.

Tri Harso Karyono. (2010). KENYAMANAN TERMAL DALAM ARSITEKTUR TROPIS. Academia.Edu, $1-8$. 